\title{
Análise das manifestações patológicas em viaduto: estudo de caso em Barretos-SP.
}

\author{
Gonçalves. G. H. V. ${ }^{1 *}$, Rocha. L. B. G. da. ${ }^{1}$, Marques Neto. J. da C. ${ }^{1}$, Serra. S. M. B. ${ }^{1}$ \\ *Autor de Contato: gustavovital@hotmail.com.br \\ ${ }^{1}$ Programa de Pós Graduação em Engenharia Civil, Universidade Federal de São Carlos, São Carlos, Brasil
}

\begin{abstract}
RESUMO
As obras de arte especiais são estruturas que se encontram diretamente expostas à ação de agentes agressivos, estando sujeitas à deterioração dos elementos estruturais. O presente artigo refere-se a um estudo de caso realizado em um viaduto no município de Barretos, SP , cujo objetivo foi identificar, analisar as causas e propor terapias para as manifestações patológicas encontradas na estrutura do viaduto. Foi utilizada a metodologia proposta por Lichtenstein (1985), que se fundamenta em três etapas: análises de subsídio, diagnóstico e definição da conduta. Diversas manifestações patológicas foram observadas no viaduto, como corrosão da armadura, desplacamento do concreto, bolor, eflorescência, ninho de concretagem e fissuras. Conclui-se que existe a necessidade de realização de manutenções no viaduto, a fim de manter a estabilidade da estrutura e a segurança dos usuários.
\end{abstract}

Palavras chave: Viadutos; Manutenção preventiva; Corrosão; Anomalias; Obras de arte. 


\begin{abstract}
The works of art are special structures that are directly exposed to the action of aggressive agents, being subject to the deterioration of two structural elements. Or this article refers to a case study carried out on a viaduct outside the municipality of Barretos, SP, whose objective was to identify, analyze the causes and provide therapies for the pathological manifestations found in the structure of the viaduct. The methodology proposed by Lichtenstein (1985) was used, which is based on three stages: subsidy analysis, diagnosis and definition of conduct. Several pathological manifestations observed are not feasible, such as reinforcement corrosion, displacement of concrete, mold, efflorescence, concreting nest and cracks. It was concluded that there is a need to carry out impracticable maintenance, in order to maintain the stability of the structure and the safety of two users.
\end{abstract}

Keywords: Viaducts; Preventive maintenance; Corrosion; Anomalies; Works of art.

\title{
RESUMEN
}

Las obras de arte especiales son estructuras que están directamente expuestas a la acción de agentes agresivos, estando sujetas al deterioro de los elementos estructurales. Este artículo hace referencia a un estudio de caso realizado sobre un viaducto en el municipio de Barretos, SP, cuyo objetivo fue identificar, analizar las causas y proponer terapias para las manifestaciones patológicas encontradas en la estructura del viaducto. Se utilizó la metodología propuesta por Lichtenstein (1985), que se basa en tres etapas: análisis de subsidio, diagnóstico y definición de conducta. Se observaron diversas manifestaciones patológicas en el viaducto, como corrosión de armaduras, desconchado del hormigón, moho, eflorescencias, nido de hormigonado y fisuras. Se concluye que existe la necesidad de realizar el mantenimiento del viaducto, con el fin de mantener la estabilidad de la estructura y la seguridad de los usuarios.

Palabras llave: Viaductos; Manutención preventiva; Corrosión; Anomalías; Obras de arte.

\section{INTRODUÇÃO}

As obras de arte encontram-se expostas à agentes de deterioração e suscetíveis a manifestações patológicas diariamente, tal fato contribui diretamente para a redução de sua vida útil (SANTOS, 2017). Segundo a ABNT NBR 15575-1:2013 (ABNT, 2013), a vida útil de uma edificação consiste no período de tempo em que ela se mantém em condições de uso, durante as atividades para as quais foram projetadas e construídas. Este período pode variar em função de alguns fatores, como as características dos materiais utilizados, qualidade da construção, uso correto da edificação e manutenção das estruturas.

Segundo Iantas (2010), a falta de manutenção periódica é um dos fatores que permite que pequenas manifestações patológicas evoluam para problemas que prejudicam o desempenho da edificação, colocando em risco sua segurança estrutural, danificando sua estética, além de elevar o custo para a recuperação de sua estrutura.

No Brasil, a ausência de programas voltados à manutenção leva os órgãos responsáveis pelas obras públicas a priorizarem apenas a execução, desconsiderando a implementação de medidas relacionadas à conservação das edificações. Tal fato pode ser observado em obras de infraestrutura, especificamente as pontes e viadutos, visto que a falta de conservação dessas obras consiste em um dos maiores problemas enfrentados pelo sistema rodoviário (VITÓRIO, 2006). 
Conhecidos como Obras de Arte Especiais (OAE), viadutos e pontes são edificações públicas importantes para o funcionamento de diversos sistemas viários. Suas estruturas podem ser constituídas de aço, madeira, concreto armado ou concreto protendido (MASCARENHAS et al., 2019).

De acordo com Laner (2001), os viadutos podem ser considerados verdadeiros equipamentos urbanos, promovendo melhores escoamentos das vias, vencendo acidentes geográficos e articulando cruzamentos. No entanto, suas estruturas possuem alto custo de construção, manutenção e recuperação.

A má gestão relacionada a conservação das OAEs vem gerando danos incalculáveis às estruturas, além de expor os usuários a riscos graves. Somente em 2018, dois viadutos de grande porte tiveram colapso parcial de suas estruturas. Tais acontecimentos, que ocorreram no viaduto do Eixão do Sul em Brasília e no Viaduto da marginal Pinheiro em São Paulo, poderiam ter sido evitados caso houvesse inspeções frequentes e realização de manutenções preventivas na estrutura (IBRAOP, 2018).

Diante do exposto, este trabalho tem como objetivo realizar um estudo de caso em um viaduto localizado no município de Barretos, SP, com o intuito de analisar as manifestações patológicas, identificar as causas e propor possíveis intervenções de reparo nessa edificação.

\section{METODOLOGIA}

Apresenta-se neste capítulo a metodologia adotada no trabalho. Realizou-se um estudo de caso para detectar e analisar as manifestações patológicas em um viaduto localizado na cidade de Barretos, SP. Para isso, foram realizadas inspeções visuais e registros fotográficos das manifestações encontradas.

\subsection{Local de realização do estudo de caso}

O viaduto está localizado na Rodovia Assis Chateaubriand (SP 425) no km 94, no município de Barretos, SP, que faz ligação com a cidade de Guaíra, SP. O microclima da cidade é caracterizado por estações com precipitação quentes e abafadas, enquanto estações de seca possuem temperaturas menores e clima árido.

$\mathrm{O}$ viaduto escolhido foi construído em concreto armado e apresenta uma grande quantidade de manifestações patológicas em sua estrutura. A Figura 1 apresenta a imagem do viaduto inspecionado.

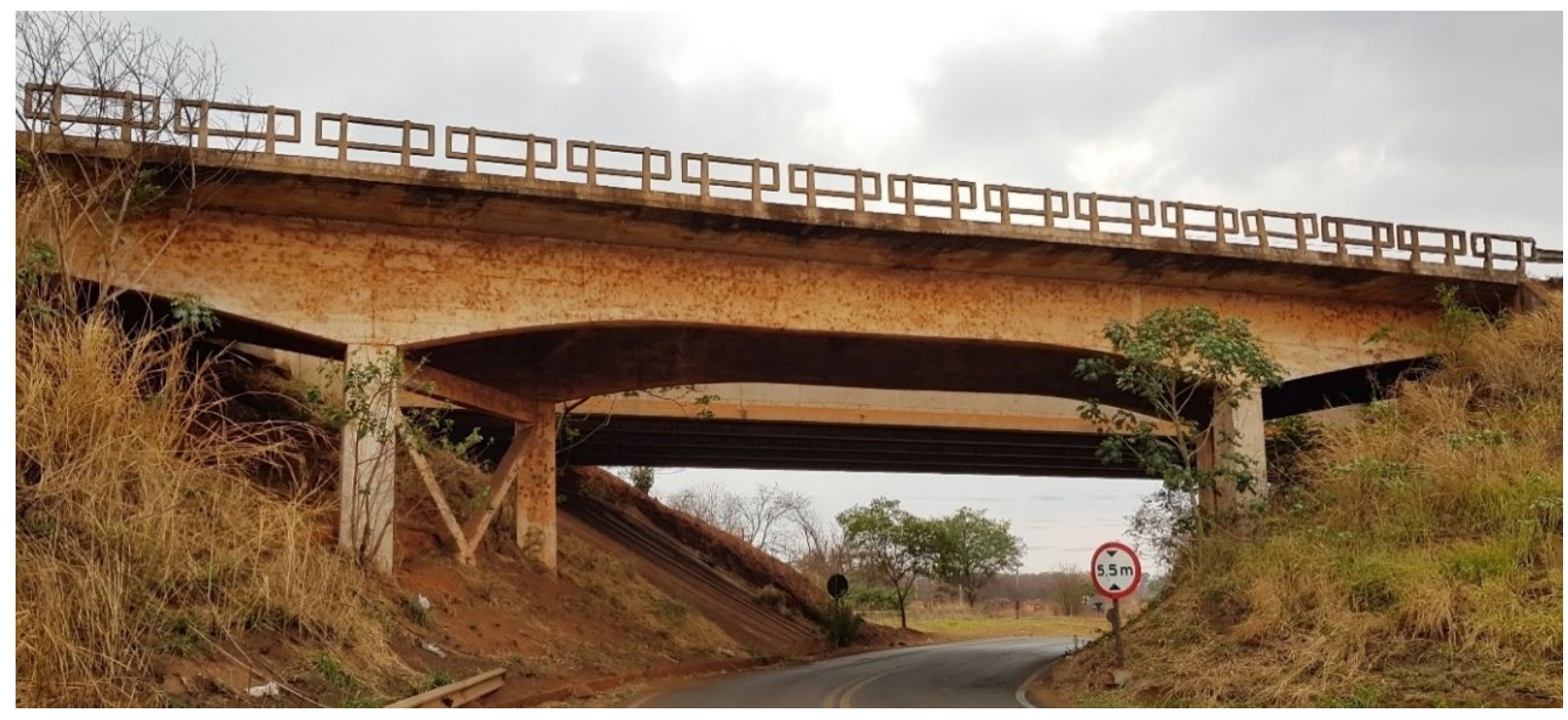

Figura 1. Viaduto em Barretos, SP 


\subsection{Método adotado para a realização do estudo de caso}

Para realizar as análises e diagnosticar as anomalias presentes no viaduto em que foi realizado o presente estudo de caso, foi adotado o método de análise de manifestações patológicas de Lichtenstein. Este método consiste em uma sequência de três etapas: o levantamento de subsídios, a elaboração do diagnóstico e a definição da conduta a ser seguida.

A etapa de levantamento de subsídios consiste em coletar as informações necessárias para o entendimento das manifestações patológicas. Essas informações podem ser obtidas por meio de vistorias no local, anamnese do caso, em que se realiza um levantamento histórico sobre a obra, resultado das análises e a realização de ensaios complementares, que ajudam na identificação da manifestação patológica (LICHTENSTEIN, 1985).

O diagnóstico tem como objetivo o entendimento e a delimitação de um quadro geral de fenômenos e manifestações. Pode ser descrito como um processo de geração de hipóteses a partir da análise dos dados coletados na etapa anterior, até que se chegue a uma correlação de prováveis manifestações patológicas com os sintomas encontrados (LICHTENSTEIN, 1985).

A última etapa do processo de análise de manifestações patológicas é a definição da conduta a ser seguida. Nesta etapa, são levantadas as hipóteses de evolução do problema, estabelecendo uma proposta de intervenção (LICHTENSTEIN, 1985).

\subsection{Levantamento de subsídios, diagnóstico e definição de conduta}

Foram realizadas vistorias nos dias 15/08/2020 e 15/10/2020, e através de inspeção visual in loco e registros fotográficos, analisou-se as manifestações patológicas encontradas no viaduto.

Além das vistorias, foram realizadas pesquisas junto aos órgãos públicos da cidade de Barretos, SP acerca do histórico da edificação, com o propósito de fazer uma anamnese do viaduto, a fim de se obter informações sobre quando a estrutura foi construída e se havia registros de manutenção.

Posteriormente, os dados coletados foram discutidos, avaliados e as possíveis causas foram determinadas. Também foram apontados os ensaios que devem ser realizados para constatação de cada manifestação patológica.

Em seguida, foram indicados os possíveis procedimentos e terapias que podem ser utilizados para a recuperação dos locais do viaduto onde houve ataques das manifestações patológicas.

\section{RESULTADOS E DISCUSSÃO}

Nesta seção, são apresentados e analisados os resultados obtidos das inspeções in loco e das fotografias registradas, identificando quais as possíveis causas das principais manifestações patológicas encontradas no viaduto, e indicando possíveis terapias.

\subsection{Levantamento histórico do viaduto}

Foram realizadas pesquisas na prefeitura da cidade de Barretos, SP e no Departamento de Estradas e Rodagem (DER), no entanto, não foram encontrados documentos, memoriais, projetos ou demais registros acerca da construção da obra ou de manutenções realizadas durante sua vida útil. A única informação encontrada a respeito do viaduto foi a de que a responsabilidade e administração da obra foi de um extinto órgão privado. Diante disso, as análises das manifestações patológicas foram realizadas levando-se em consideração somente as inspeções visuais.

\subsection{Manifestações patológicas encontradas na superestrutura do Viaduto}

\subsubsection{Tabuleiro Superior do Viaduto}

No tabuleiro superior do viaduto, foi observado que algumas partes do guarda corpo encontravamse completamente danificadas, como mostra a Figura 2a. Observou-se que houve a perda total da seção de concreto e as armaduras encontram-se expostas. Além disso, na extremidade do viaduto 
há uma grande trinca por toda extensão transversal do pavimento asfáltico, como indicado na Figura $2 b$.

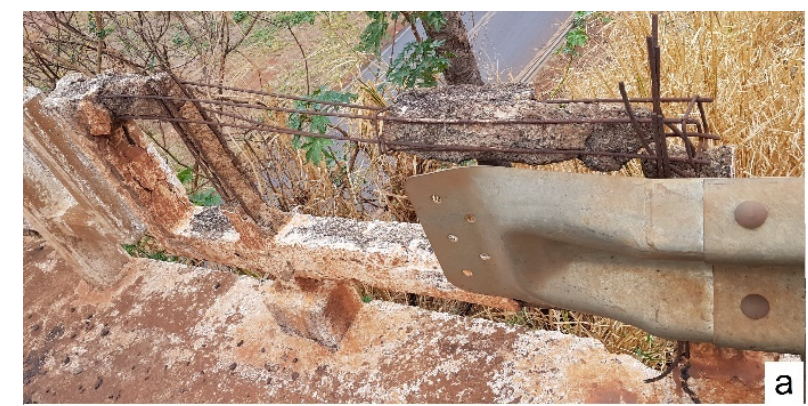

Figura 2 - (a) Corrosão da armadura do guarda-corpo (b) problemas na plataforma do tabuleiro

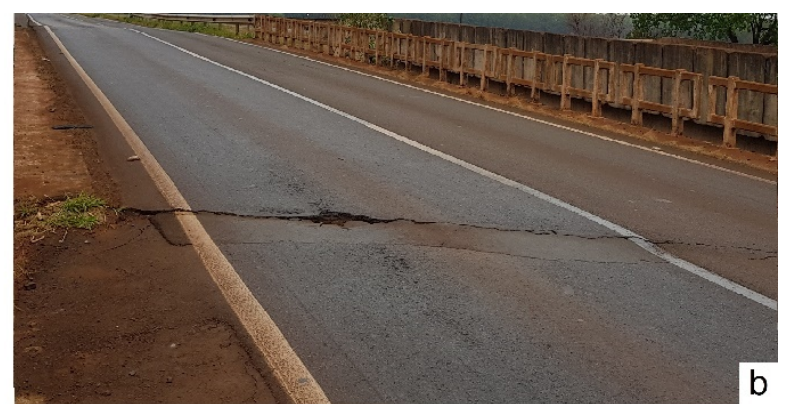

O guarda-corpo do Viaduto, apresentado na Figura 4a, possui contato direto com a ação da água da chuva, ou seja, possivelmente não houve o tratamento da superfície do concreto, deixando o elemento totalmente exposto a intempéries. Nesse caso, também é provável que os guarda-corpos tenham sofrido ataques por carbonatação, visto que o viaduto está exposto a um ambiente com alta concentração de $\mathrm{CO} 2$, decorrente do alto fluxo de veículos que o utilizam.

Durante o processo de corrosão, o aço se expande em relação ao seu tamanho original, o que, consequentemente, pode ter ocasionado o desplacamento do concreto. Além disso, esta estrutura pode ter sido submetida a causas externas, como impactos, vandalismo, temporais e outros ataques. A trinca no asfalto, apresentada na Figura 4b, está localizada na divisa do pavimento da rodovia com o viaduto, portanto, o que pode ter provocado a abertura dessa região do asfalto foi a movimentação da estrutura do viaduto, devido ao carregamento dos veículos e movimentações térmicas da estrutura. Este problema também foi observado por Paixão et al. (2020) no Viaduto do Café em São Luís, MA, evidenciando a baixa realização de manutenções nos pavimentos dos viadutos.

\subsubsection{Tabuleiro inferior do viaduto}

Na laje do tabuleiro inferior do viaduto, exibida na Figura 3a, é possível observar que houve o processo de corrosão da armadura em alguns pontos, considerando-se o aparecimento de manchas de ferrugem na estrutura e pela exposição da armadura. Além disso, foi verificado a presença de umidade em todos os locais onde existem exposição da armadura.

Como mostrado na Figura 3b, observou-se que em uma das transversinas também houve o desplacamento da camada de cobrimento, exibindo parte da armadura e, inclusive, barras que foram rompidas, indicando que possivelmente, houve o processo de corrosão da armadura.
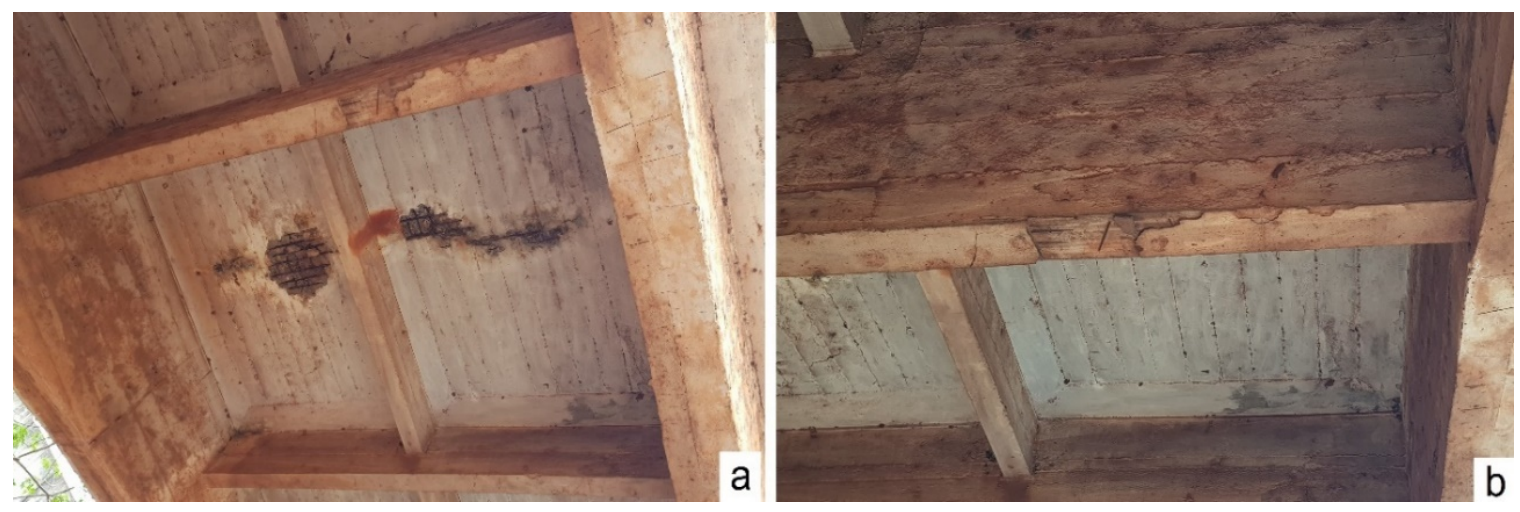

Figura 3. (a) Corrosão da armadura na laje (b) corrosão da armadura na transversina 
A umidade presente na estrutura foi um dos fatores críticos para o processo corrosivo das armaduras da laje e da transversina. Eventualmente, essa umidade é originada da água que penetra pela trinca formada no pavimento ou também por falha no sistema de drenagem do viaduto, o que faz com que água percole pelo tabuleiro, tal fato indica que o sistema de impermeabilização da estrutura é falho. Além disso, por ser uma estrutura antiga, há a possibilidade de que a camada de concreto de cobrimento não seja suficiente para a proteção da armadura, deixando a estrutura vulnerável a ataques de agentes agressivos.

Essa região do viaduto também pode ter sido sujeita a ataques de carbonatação, contribuindo para despassivação da armadura. Além disso, devido ao processo corrosivo da armadura, houve uma expansão do aço, ocasionando desplacamento do concreto de cobrimento, deixando a armadura exposta ao meio.

Em análises realizadas por Pintan (2013) em OAEs localizadas no município de Recife, PE, também foram observadas estruturas que apresentavam corrosão da armadura, devido a presença de umidade na estrutura e pela alta concentração de CO2 no ambiente.

\subsubsection{Balanço lateral do viaduto}

Nas vigas, lajes e balanços laterais da superestrutura do viaduto, foi observada a existência de bolor e eflorescência, assim como áreas em que, possivelmente, houve corrosão da armadura, visto que existem manchas de ferrugem na superfície. A Figura 4 exibe um dos locais mais afetados por estas manifestações patológicas.

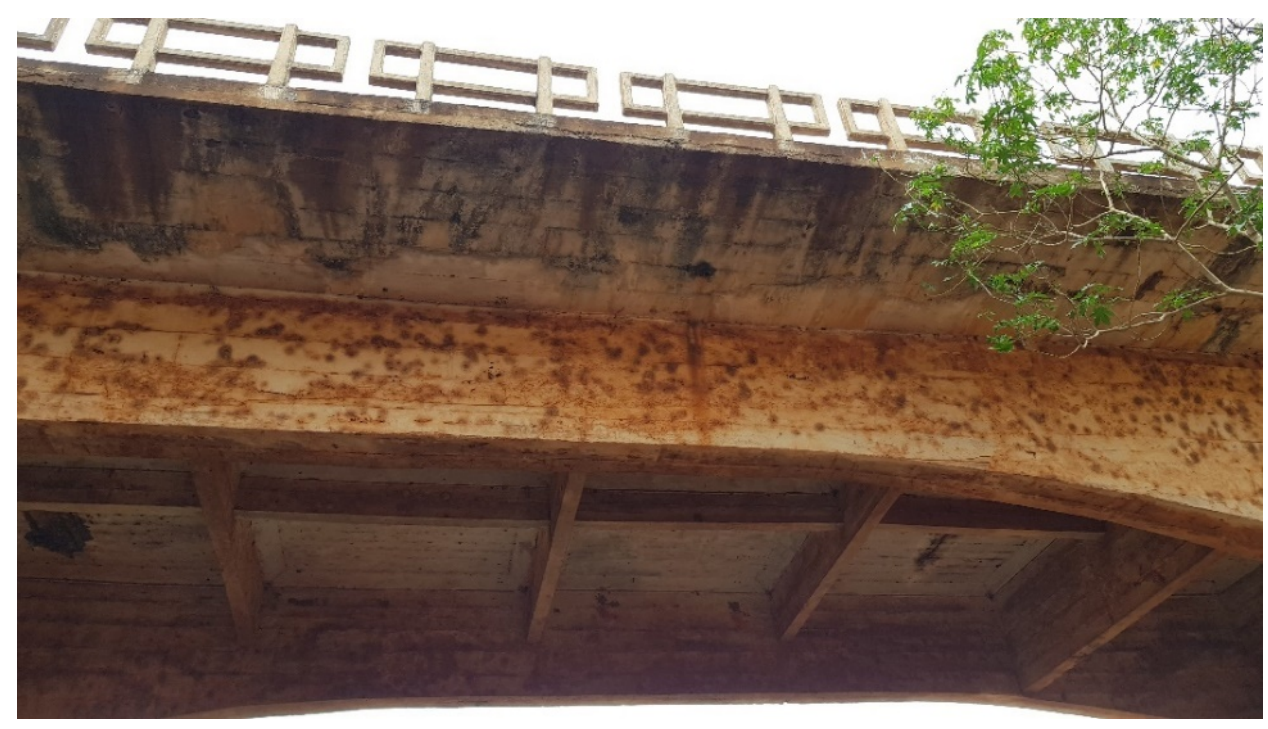

Figura 4. Bolor, eflorescência e manchas de ferrugem presentes no viaduto

O bolor e a eflorescência também são manifestações patológicas oriundas da presença de umidade. Estas manifestações patológicas podem ter sido ocasionadas pela falta de impermeabilização da estrutura e ineficiência dos drenos, os quais se encontram obstruídos e apresentam diâmetro pequeno, de modo que a água que escoa da plataforma se acumula nessa região do balanço, percolando a estrutura do viaduto. Além disso, essa área da estrutura está diretamente exposta à ação de chuvas, contribuindo para o acúmulo da umidade.

A ineficiência de drenos, semelhante às encontradas neste trabalho, também foi observada por Silva (2016) em análises realizadas em alguns viadutos de Recife, PE, nos quais a obstrução dos drenos provocou infiltrações no balanço da laje do tabuleiro, levando ao aparecimento de bolor e 
eflorescência. Diante disso, o funcionamento adequado do sistema de drenagem do viaduto é imprescindível, de forma a evitar o acúmulo de umidade.

A presença de manchas de ferrugem na viga, como observado na Figura 6, pode ser indício de corrosão da armadura que, eventualmente, foi ocasionada pela exposição da estrutura a intempéries e por ataques de carbonatação. A camada do concreto de cobrimento também pode ter contribuído para o processo corrosivo. Porém, como essa área não apresenta desplacamento do concreto e armadura exposta, é necessário realizar um estudo mais aprofundado, a fim de identificar se realmente está ocorrendo corrosão no local.

\subsection{Manifestações Patológicas encontradas na mesoestrutura do viaduto}

Foram encontradas diversas fissuras nos elementos estruturais do viaduto. Na Figura 5a, é possível observar a formação de uma fissura na estrutura de travamento do viaduto. Em um dos pilares, nota-se a presença de ninhos de concretagem e manchas de ferrugem, como mostra a Figura $5 \mathrm{~b}$.
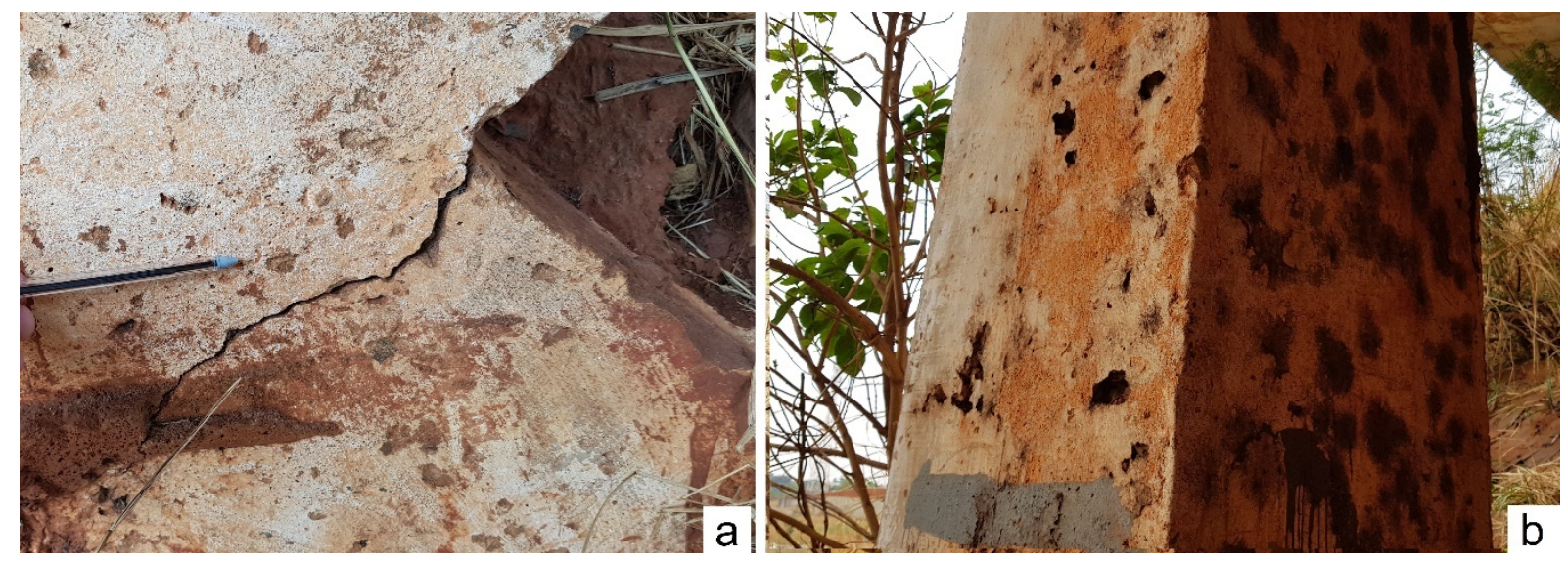

Figura 5 (a) Fissuras no viaduto (b) ninhos de concretagem

Como observado na Figura 5a, existe uma fissura no concreto na estrutura de travamento dos pilares. Eventualmente, ela pode ter sido ocasionada por recalque diferencial da fundação da estrutura ou pelo excesso de carregamento. Entretanto, para que seja possível diagnosticar corretamente a causa de uma fissura, é necessário que se realize um monitoramento mais preciso das aberturas.

Assim como em outras áreas do viaduto, o pilar indicado na Figura 5 b está exposto ao $\mathrm{CO} 2$ presente no ambiente e à ação da água da chuva, propiciando ataques por carbonatação, o que pode ter ocasionado o processo de corrosão da armadura em alguns pontos, evidenciados pela presença de manchas de ferrugem na superfície do concreto. Neste contexto, o fator que pode ter colaborado para entrada de agentes agressivos na peça são os ninhos de concretagem presentes na estrutura, causados por falhas durante a execução da concretagem, visto que as manchas de ferrugem se localizam próximo a eles.

\subsection{Sugestões de ensaios e terapias a serem realizadas nos locais onde há presença de manifestações patológicas}

Para realizar o tratamento correto e a restauração da estrutura, é necessário identificar o agente agressivo por meio de ensaios e estabelecer um diagnóstico para efetuar a correção necessária. Para 
que o viaduto continue em funcionamento durante os estudos de identificação das manifestações patológicas, recomenda-se a utilização de ensaios não destrutivos.

\subsubsection{Pontos de corrosão}

Para identificar as causas do surgimento de corrosão das armaduras, é indicado que seja realizado o ensaio de carbonatação, por meio da verificação da profundidade da frente de carbonatação. Outro ensaio indicado para se obter um diagnóstico mais preciso é o de pacometria, para verificar a espessura do concreto de cobrimento. Desta maneira, pode-se obter dados importantes para analisar a situação dos pontos onde se evidenciam a corrosão do aço e adotar a estratégia correta de restauração do local.

De qualquer modo, as seções do guarda-corpo que foram totalmente deterioradas deverão ser reconstituídas. É importante que seja feito o tratamento das armaduras com inibidores de corrosão, assim como a impermeabilização do concreto, de forma a evitar o ressurgimento do problema.

Para a recuperação da laje e da transversina que apresentam armadura exposta, indica-se a remoção de todo o concreto deteriorado e dos produtos de corrosão. Caso tenha ocorrido perda de seção das armaduras superior a $10 \%$ de sua área, recomenda-se a substituição por novas barras de aço, dimensionadas de acordo com a norma NBR 6118 (ABNT, 2014). As armaduras da transversina que foram rompidas deverão ser obrigatoriamente substituídas. Para proteção das armaduras, recomenda-se a aplicação de inibidores de corrosão a base de zinco, como o primer epóxi.

Após o procedimento de restauração das barras de aço, pode ser utilizado argamassa polimérica ou graute como forma de reparo do concreto, dependendo da profundidade do dano. Outra alternativa seria a utilização de concreto projetado, seguindo os métodos apresentados na NBR 14026 (ABNT, 2012).

Para evitar que o problema volte a surgir é de extrema importância que o pavimento asfáltico seja restaurado, pois a trinca é porta de entrada para a infiltração de água, prejudicando a estrutura do viaduto.

Para os locais onde não há exposição de armaduras, mas há presença de manchas de ferrugem no concreto, é necessário que sejam realizados ensaios específicos para constatar se está havendo corrosão da armadura, como o ensaio de potencial de corrosão.

\subsubsection{Bolor e eflorescência}

É necessário realizar a limpeza nos locais atingidos por fungos no concreto e removê-los. Para isso, pode-se realizar a lavagem dos locais afetados com solução de hipoclorito de sódio e, após o bolor ser removido, é necessário impermeabilizar corretamente a estrutura.

Para a remoção da eflorescência, pode-se realizar a limpeza através de jateamento de água ou escovação do local atingido, utilizando uma escova dura e seca. Em casos mais extremos, recomenda-se fazer o uso de soluções diluídas com ácido, tomando todos os devidos cuidados com a estrutura.

Para evitar a reincidência dessas manifestações, recomenda-se fazer a aplicação de material hidrofugante em toda a estrutura, visando impedir a infiltração da água no concreto. Também é importante que os drenos sejam desobstruídos e reparados, tendo em vista sua importância para prevenir a ação da água na estrutura.

\subsubsection{Fissuras}

Para realizar o tratamento das fissuras, deve-se obter um diagnóstico correto da causa. Para tanto, é necessário identificar sua profundidade e realizar uma análise da abertura, observando se a fissura está ativa ou não. Para realizar este monitoramento da fissura, podem ser utilizados ensaios com lâminas de vidro. Após o conhecimento da situação da fissura e a definição das prováveis causas, 
é necessário designar os métodos corretos de restauração a serem realizados na estrutura. Além disso, é imprescindível que o reparo das fissuras seja realizado rapidamente, visto que ela pode ser porta de entrada para agentes agressivos.

\section{CONCLUSÃO}

Dando importância ao objetivo proposto neste estudo de caso, que foi identificar e analisar manifestações patológicas de um viaduto no município de Barretos, SP, por meio do método de Lichtenstein, e propor terapias para os problemas encontrados, verifica-se que a metodologia adotada se mostrou eficiente para este estudo.

Todavia, não foi possível obter informações sobre o histórico do viaduto e não foram realizados ensaios para comprovar as causas das manifestações patológicas, dificultando a elaboração de diagnósticos precisos, visto que as análises foram realizadas apenas por inspeções visuais.

Apesar disso, verificou-se que o viaduto se encontra em más condições. Este fato é constatado devido ao número significante de manifestações patológicas encontradas. Dentre as manifestações identificadas no viaduto, foram detectadas as seguintes: ocorrência de corrosão da armadura, desplacamento do concreto, eflorescência, bolor, fissuras e ninho de concretagem.

A maioria das manifestações encontradas podem ter sido geradas devido à alta incidência da umidade na estrutura e a alta concentração de $\mathrm{CO} 2$ no local, consequência do grande fluxo de veículos. Além disso, o Viaduto aparenta ser uma construção antiga, logo, pressupõe-se que o cobrimento do concreto, definido na fase de projeto, não é suficiente para a proteção da armadura, fator que pode ter acelerado o desenvolvimento das manifestações patológicas. O sistema de impermeabilização e de drenagem do viaduto também mostraram ser falhos.

Em síntese, de acordo com os resultados encontrados, pode-se dizer que a falta de inspeções e manutenções regulares foram fatores que contribuíram significativamente para o aumento das manifestações patológicas no viaduto, o que reforça a importância da implementação de programas voltados para a manutenção preventiva das obras de artes.

A partir das circunstâncias do viaduto e dos resultados obtidos pela análise, conclui-se que a estrutura precisa passar por um rigoroso programa de manutenção, de forma a manter o desempenho e aumentar a vida útil da estrutura, visto que a demora em iniciar os reparos adequados nesse viaduto pode comprometer sua estabilidade, colocando a segurança dos usuários em risco. Para pesquisas futuras, sugere-se a realização dos ensaios indicados para constatação das manifestações patológicas, com ênfase no monitoramento das fissuras, além dos ensaios para identificação de corrosão da armadura, visto que a estrutura apresenta uma alta quantidade de manchas de ferrugem, sendo importante realizar um estudo preciso nessa área.

\section{REFERÊNCIAS}

ANDRADE, C. B. F. Manifestações patológicas das estruturas de concreto armado. 2013. $42 \mathrm{f}$. Monografia (Especialização) - Curso de Engenharia Civil, Escola de Engenharia, Universidade Federal de Minas Gerais, Belo Horizonte, 2013.

ANDRADE, T.; SILVA, A. J. C. e. Patologia das estruturas. In: ISAIA, Geraldo C. (Ed). Concreto: Ensino, Pesquisa e Realizações. v. 2. São Paulo, SP: IBRACON, 2005. Cap. 32, p. 953 - 983.

ARAUJO, C. J. R. V. Principais aspectos abordados na ABNT NBR 9452:2016, a importância das atividades de manutenção em pontes e viadutos e as dificuldades das condições de acesso às inspeções. Revista IPT, São Paulo, v. 1, n. 5, p. 17-40, ago. 2017. Disponível em: http://revista.ipt.br/index.php/revistaIPT/article/view/42/46. Acesso em: 30 ago. 2020. 
ASSOCIAÇÃO BRASILEIRA DE NORMAS TÉCNICAS. NBR 6118:2014: Projeto de estruturas de concreto - Procedimento. Rio de Janeiro, 2014. 238 p.

ASSOCIAÇÃO BRASILEIRA DE NORMAS TÉCNICAS. NBR 14026:2012: Concreto Projetado - Especificação. 2 ed. Rio de Janeiro, 2012. 8 p.

ASSOCIAÇÃO BRASILEIRA DE NORMAS TÉCNICAS. NBR 15575-1:2013: Edificações habitacionais - Desempenho - Requisitos gerais. 1 ed. Rio de Janeiro, 2013. 71 p.

BASTOS, H. C. N.; MIRANDA, M. Z. Principais patologias em estruturas de concreto de pontes e viadutos: manuseio e manutenção das obras de arte especiais. Construindo, Belo Horizonte, v. 9, p. 93-101, jul. 2017.

FÉDÉRATION INTERNATIONALE DU BÉTO. (FIB 53) Structural Concrete Textbook on behaviour, design and performance. Second edition, Volume 3: Design of durable concrete structures, 2010, $390 \mathrm{p}$.

HELENE, P. R. L. Manual de reabilitação de Estruturas de Concreto: Reparo, Reforço e Proteção. 2. ed. São Paulo: Red Rehabilitar, editores, 2003. 718p.

IANTAS, L. C. Estudo de caso: Análise de Patologias estruturais em edificação de gestão pública. 2010. 57 f. Monografia (Especialização) - Curso de Especialização em Construção de Obras Públicas, Universidade do Paraná, Curitiba, 2010.

INSTITUTO BRASILEIRO DE AUDITORIA DE OBRAS PÚBLICAS. Sobre a queda do viaduto da marginal em São Paulo. 2018. Disponível em: http://www.ibraop.org.br/sobre-a-queda-doviaduto-da-marginal-em-sao-paulo/. Acesso em: 17 ago. 2020.

LANER, F. J. Manifestações patológicas nos viadutos, pontes e passarelas no município de Porto Alegre. 2001. 145 f. Dissertação (Mestrado) - Curso de Engenharia Civil, Universidade Federal do Rio Grande do Sul, Porto Alegra, 2001.

LICHTENSTEIN, N. B. Patologia das construções: procedimento para formulação do diagnóstico de falhas e definição de conduta adequada à recuperação de edificações. 1985. 31 f. Dissertação (Mestrado) - Universidade de São Paulo, 1985.

LORENZI, A.; REGINATO, L.A.; LORENZI, L.s.; SILVA FILHO, L.C.P. Emprego de Ensaios Não Destrutivos para Inspeção de Estruturas de Concreto. Revista de Engenharia Civil Imed, [S.L.], v. 3, n. 1, p. 3-13, 30 jun. 2016.

LOURENÇO, L. C.; ALVES, V. R.; JORDY, J. C.; MENDES, L. C. Parâmetros de avaliação de patologias em obras-de-arte especiais. Engenharia Civil, [S. L.], n. 34, p. 5-14, 2009.

MASCARENHAS, F. J. R.; CORTEZÃO, A. W. S.; AZEVEDO JÚNIOR, A. P.; ANDRADE, B. D.; OLIVEIRA, L. F.; VIANA, P. S. Patologias e inspeção de pontes em concreto armado: Estudo de caso da ponte Governador Magalhães Pinto. Engevista, [S. 1.], v. 21, n. 2, p. 288-302, maio 2019. 
MATTOS, T. S. Programa para análise de superestruturas de pontes de concreto armado e protendido. 2001. 156 f. Dissertação (Mestrado) - Curso de Engenharia Civil, Universidade Federal do Rio de Janeiro, Rio de Janeiro, 2001.

MEDEIROS, M. H. F.; ANDRADE, J. J. O.; HELENE, P. Durabilidade e Vida Útil das Estruturas de Concreto. In: ISAIA, G. C. Concreto: Ciência e Tecnologia. São Paulo: IBRACON, 2011. Cap. 22, p. $773-808$.

NADALINI, A. C. V.; BISPO, A. O. Patologias em estruturas de concreto armado em ambiente marítimo. In: COBREAP. Inovações Científicas e Tecnológicas. Foz do Iguaçu, 2017. p. 1-25.

PAIXÃO, M. A. S.; BORBA, F. V.; ROCHA, J. P.; LIMA, K. B. A.; ARAÚJO, W. M. P.; VIANA, S. W. J. P.; FILHO, L. T. S. P. Manifestações Patológicas em obras de arte especiais: Estudo de caso de um viaduto Rodoviário em São Luís-MA. Revista Cientifica multidisciplinar Núcleo do Conhecimento, São Luís, v. 5, p. 132-147, abr. 2020. Disponível em: https://www.nucleodoconhecimento.com.br/engenharia-civil/viaduto-rodoviario. Acesso em: 20 out. 2020.

PETRY, S. B. Estudo da permeabilidade à água na camada de cobrimento de protótipos de concretos com altos teores de cinza volante. 2004. 94 f. Dissertação (Mestrado) - Curso de Engenharia Civil, Universidade Federal de Santa Maria, Santa Maria, 2004.

PFEIL, W. Pontes em concreto armado. Rio de Janeiro: Livros Técnicos e Científicos, 1993.

PINTAN, N. M. Manifestações Patológicas e estudo da corrosão presente em pontes do recife. 2013. 174 f. Dissertação (Mestrado) - Curso de Engenharia Civil, Universidade de Pernambuco, Recife, 2013.

ROQUE, J. A.; MORENO JUNIOR, A. L. Considerações sobre vida útil do concreto. In: ENCONTRO NACIONAL DE PESQUISA-PROJETO-PRODUÇÃO EM CONCRETO PRÉMOLDADO, 1., 2005, São Carlos. Anais. Campinas: Encontro Nacional de Pesquisa-ProjetoProdução em Concreto Pré-Moldado, 2005. p. 1-11.

SANTOS, F. M. A. Impactos da Aplicação da ABNT NBR 15.575/2013 nas Empresas de Edificações. 2017. 136 f. Dissertação (Mestrado) - Programa de Pós-Graduação em Ambiente Construído, Universidade Federal de Juiz de Fora, Juiz de Fora, 2017.

SILVA, C. J. G. Uma amostra das condições estruturais e funcionais de pontes e viadutos das rodovias federais de pernambuco. 2016. 138 f. Dissertação (Mestrado) - Curso de Engenharia Civil, Universidade de Pernambuco, Recife, 2016.

SITTER, W. R. Costs for Srevice Life Optimization. The "Law of Five". In: CEBRILEM Durability of Concrete Structures. Proceedings of the Internacional Workshop held in Copenhagen, 1-20 May 1983. P. 131-134, Copenhagen, CEB, 1984. (Workshop Reported by Steen Rostam).

SOUZA, V. C. M.; RIPPER, T. Patologia, recuperação e reforço de estruturas de concreto. São Paulo: Pini, 1998. 
VITÓRIO, A. Fundamentos da patologia das estruturas nas perícias de engenharia. Instituto Pernambucano de Avaliações e Perícias de Engenharia. Recife, 2003.

VITÓRIO, A. Vistorias, Conservação e Gestão de Pontes e Viadutos de Concreto. Anais do $48^{\circ}$ Congresso Brasileiro do Concreto, 2006.

WAJDOWICZ, C. C. Elaboração de estrutura analítica de partição (EAP) para orçamentos referentes à recuperação das principais manifestações patológicas em pontes e viadutos de concreto armado. 135 f. Dissertação (Mestrado) - Curso de Engenharia Civil, Universidade Federal do Paraná, Curitiba, 2017.

YAZIGI, R. Avaliação de carbonatação em viadutos em concreto armado. 2008. 185 f. Tese (Doutorado) - Curso de Engenharia de Infra-Estrutura Aeronáutica, Instituto Tecnológico de Aeronáutica, São José dos Campos, 2008. 